\title{
Descriptive study of non-fatal interpersonal violence in a Nigerian City
}

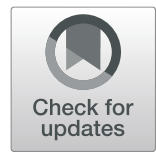

\author{
Nnaemeka Thaddeus Onyishi (iD and Samuel Robsam Ohayi
}

\begin{abstract}
Background: Interpersonal violence is rampant in our society such that the news media is constantly awash with reports of violent incidents. Understanding the peculiarities of violence in a given population is key to devising effective preventive measures. This is a descriptive study of assault victims referred by the police to the Clinical Forensic unit of a University Teaching Hospital. Structured interview using preset questions was conducted on each assault victim. Data obtained was analyzed with IBM SPSS statistics version 20. Descriptive analysis and tests of statistical significance were done as appropriate. This study aimed to determine the peculiar characteristics of interpersonal violence in Enugu, southeastern Nigeria.

Results: There were 220 victims and 471 assailants in the study. The age range of victims was 6-80 years and mean age (SD) was 33 (12.5) years. The age range of assailants was 15-65 years with mean age (SD) 34.2 (9.5) years. More males than females were involved either as victims $(P=0.02)$ or as assailants $(P<0.001)$. Most of the incidents (36.8\%) occurred in residential areas followed by business or workplace-related disagreements (32\%). Land dispute was the underlying factor in $3.6 \%$ of the cases. The prevalence of intimate partner violence was rather low (2.3\%) but this may be due to under reporting. Where guns were involved, they were used as cudgel rather than fire arm.

Conclusions: Interpersonal violence often occurred in the context of and as a corollary to a person's life endeavors and daily activities. Most cases of interpersonal violence occurred in residential quarters. Males in active, productive age are mostly involved both as victims and as assailant.
\end{abstract}

Keywords: Non-fatal violence, Interpersonal violence, Violence determinants, Nigeria

\section{Background}

Violence, defined as "the intentional use of physical force or power, threatened or actual, against oneself, or against an individual or group or community" (WHO, 1996) is common in human society such that the news media has frequent reports of violent incidents.

The human cost of violence is considerable. Globally, about 1.4million people die each year from violence in all its various forms and manifestations (WHO, 2017). Also, it was estimated that 475,000 people worldwide were victims of homicide alone in 2012 giving an overall rate of 6.7 per 100,000 population (WHO, 2014). Suicide and homicide caused $2.2 \%$ of all deaths in USA in 2013 claiming about 57,270 lives (CDC, 2016).

The death burden is just a minor fraction of the total burden imposed on societies and health systems by acts of

\footnotetext{
*Correspondence: tedcoj@gmail.com

Pathology Department, Enugu State University of Science \& Technology College of Medicine, Parklane, Enugu 40001, Nigeria
}

violence because non-fatal consequences of violence dwarf the mortality statistics. In fact, a report (CDC, 2002) puts the ratio of non-fatal intentional injuries to homicides at 94:1 just as the Global burden of disease study 2013 records a huge number (5.4 billion) of cases and sequelae of violence-related injuries (Vos et al., 2015).

Violence, in addition to being a criminal justice and human right issue, has been recognized as a leading global public health problem by World Health Assembly through its resolution (WHA 49.25). Thus a public health approach, which involves systematic data collection and analysis to determine its magnitude, characteristic features and risk factors, is a useful strategy for its containment. To the best of our knowledge, no study in our region of Nigeria has examined the epidemiology of interpersonal violence as a whole, or the peculiarities of interpersonal violence presenting to police authorities. This work is necessary to elucidate the characteristic features of interpersonal violence, which could be exploited 
in designing a preventive measure. Therefore, this work aimed to determine the demographics, peculiarities and underlying factors related to the phenomenon of interpersonal violence in Enugu southeastern Nigeria.

\section{Methods}

This is a descriptive study in which data was collected through structured interview, using preset questions. The study population comprised of assault victims attending the Forensic Clinic of Enugu State University Teaching Hospital, between November 1, 2013, and October 31, 2014. Enugu is the administrative capital of Enugu state, South Eastern Nigeria. It is home to people from various backgrounds and social strata and has a population of about 2 million people according to 2006 estimates. The Forensic unit is dedicated to the clinical forensic management of assault cases in the city and its environs. Victims are referred to the hospital by the police and they come with police Form D44 which is a medical report component of police case file for assault. At the hospital, victims initially present at the hospital records department where they are registered, issued with hospital case note and then directed to the forensic unit. At the forensic unit, patient's history is taken and patient is examined. Medical opinion to the police about the nature of injury sustained is entered into Form D44. In terms of treatment, the forensic unit offers care for minor wounds as major physical injuries are managed in other medical units. In addition, some victims present with wounds already treated. Victims of sexual assault are managed as per protocol. Data collection was done by doctors at the time of presentation at the forensic unit. The data collected include demographic information, setting and circumstance of violence, time of violence, number of assailants, anatomical location of injury and assault mechanism. Weapons used in the assault were coded as "assault mechanism" and were further classified into "blunt object", "sharp object" or body parts.

Ethical approval was obtained from the hospital ethics committee and informed consent was obtained from patients and for those younger than 18 years, from their parent/guardian.

Data obtained was analyzed with IBM SPSS statistics version 20. Descriptive statistics were run and results generated were presented in frequency tables. Continuous variable was compared with $t$ tests while categorical variables were analyzed with chi square, Fisher's exact and binomial tests as appropriate. $\alpha$ value was set at 0.05 , but to control for familywise error rate of 9 tests, a Bonferroni corrected $P$ value of 0.0056 or less was considered statistically significant.

\section{Results}

Two hundred twenty (220) cases or victims of non-fatal interpersonal violence were seen in the period under review. Table 1 shows the age and gender distribution of victims and assailants.

The 220 cases (victims) of assault were perpetrated (attacked) by 471 individuals. The number of assailants per case of assault ranged from 1 to 15 as shown in Table 2.

The age of victims ranged from 6 to 80 years with mean (SD) of 33.1(12.4) years. The age range of assailants was 15 to 65 years with mean (SD) of 34.2(9.5) years. The mean age of male victims was not significantly higher than that of female victims; $t(218)=2.13$, $P=0.03$. No significant difference existed in the mean age of male and female assailants; $\mathrm{t}(205)=0.33, P=$ 0.75. Paired comparison of single victim single attacker cases $(n=145)$ showed a positive correlation between the age of the victim and that of the corresponding

Table 1 The age and gender for the studied victims and assailants of the studied cases of non-fatal interpersonal violence

\begin{tabular}{|c|c|c|c|c|c|c|}
\hline \multirow{3}{*}{$\begin{array}{l}\text { Age category } \\
\text { (years) }\end{array}$} & \multicolumn{3}{|c|}{ Gender (victims) } & \multicolumn{3}{|c|}{ Gender (assailants) $^{*}$} \\
\hline & Female & Male & Total & Female(s) & Male(s) & Total \\
\hline & Count (\%) & Count (\%) & Count (\%) & Count (\%) & Count (\%) & Count (\%) \\
\hline 10 or less & $1(0.5)$ & $1(0.5)$ & $2(0.9)$ & $1(0.5)$ & $1(0.5)$ & $2(0.9)$ \\
\hline $11-20$ & $11(5.0)$ & $5(2.3)$ & $16(7.3)$ & $5(2.3)$ & $11(5.2)$ & $16(7.5)$ \\
\hline $21-30$ & $39(17.7)$ & $59(26.8)$ & $98(44.5)$ & $17(8.0)$ & $76(35.7)$ & $93(43.7)$ \\
\hline $31-40$ & $27(12.3)$ & $27(12.3)$ & $54(24.5)$ & $13(6.1)$ & 39 (18.3) & $52(24.4)$ \\
\hline $41-50$ & $12(5.5)$ & $18(8.2)$ & 30 (13.6) & $5(2.3)$ & $25(11.7)$ & $30(14.1)$ \\
\hline $51-60$ & $3(1.4)$ & $8(3.6)$ & $11(5.0)$ & $3(1.4)$ & $8(3.8)$ & $11(5.2)$ \\
\hline $61-70$ & $1(0.5)$ & $7(3.2)$ & $8(3.6)$ & $0(0.0)$ & $8(3.8)$ & $8(3.8)$ \\
\hline More than 70 & $0(0.0)$ & $1(0.5)$ & $1(0.5)$ & $0(0.0)$ & $1(0.5)$ & $1(0.5)$ \\
\hline Total & $94(42.7)$ & $126(57.3)$ & $220(100.0)$ & $44(20.7)$ & $169(79.3)$ & $213^{*}(100.0)$ \\
\hline
\end{tabular}

${ }^{*}$ Each one of the 220 victims reported being attacked by 1 or more assailants. This figure shows the 213 cases or incidents in which there was a single assailant or multiple assailants of the same gender irrespective of the numerical count of the assailants involved in each case 
Table 2 The numbers and gender of the assailants in the studied cases of non-fatal interpersonal violence

\begin{tabular}{|c|c|c|}
\hline \multicolumn{2}{|l|}{ Assailants } & \multirow{2}{*}{$\frac{\text { No of cases }}{145}$} \\
\hline Number of assailants & 1 assailant & \\
\hline & 2 to 5 assailants & 56 \\
\hline & 6 to 9 assailants & 12 \\
\hline & More than 10 assailants & 7 \\
\hline & Total & 220 \\
\hline \multirow[t]{6}{*}{ Gender combination of assailants } & 1 male assailant & 109 \\
\hline & 1 female assailant & 36 \\
\hline & $>1$ assailant, all males & 59 \\
\hline & $>1$ assailant, all females & 9 \\
\hline & $>1$ assailant, both sexes & 7 \\
\hline & Total & 220 \\
\hline
\end{tabular}

$\operatorname{attacker}(r=0.31, P=0.001)$. Pairwise, the mean age of the victim was not significantly different from that of the attacker $(\mathrm{t}=1.00 ; P=0.32)$. Significantly more males than females were involved as assailants $(P<0.001$; one sample Binomial test).Also more males than females were involved as victims $(P=0.02$; one sample Binomial test)

Table 3 shows the cross tabulation of circumstance of interpersonal violence by victim's gender.

The highest number of interpersonal violence (81/ $220 ; 36.8 \%$ ) occurred in residential areas among people who are not relatives but who share the same living quarters. Nearly $32 \%(71 / 220)$ of assault cases occurred in the setting of work- or business-related transactions. Circumstance of assault showed strong statistical association or relationship with gender of victims $\left(\chi^{2}=34.4 ; P<0.001\right)$. Also shown in Table 3 is the categorization of cases of assault in line with WHO typology of interpersonal Violence. By this categorization, $24(10.9 \%)$ cases of family violence were reported, $19(8.6 \%)$ of which were violence by non-partner while $5(2.3 \%)$ were cases of intimate partner violence. The wife was the assailant in one case of intimate partner violence while the husband was the assailant in 4 cases. Category of violence showed strong statistical association with gender of victim (Fisher's exact; $P<0.001$ ).

Table 4 shows the mechanism or weapon by which injury was produced. Blunt weapons and body parts were most frequently used as weapon of assault.

Table 3 The circumstance of assault and typology of violence studied according to the gender of the victims of non-fatal interpersonal violence

\begin{tabular}{|c|c|c|c|c|c|}
\hline \multirow[t]{3}{*}{ Variable $^{*}$} & & \multicolumn{3}{|c|}{ Gender (victims) } & \multirow[t]{3}{*}{ Test statistic } \\
\hline & & \multirow{2}{*}{$\begin{array}{l}\text { Female } \\
\text { Count (\%) }\end{array}$} & \multirow{2}{*}{$\begin{array}{l}\text { Male } \\
\text { Count (\%) }\end{array}$} & \multirow{2}{*}{$\begin{array}{l}\text { Total } \\
\text { Count (\%) }\end{array}$} & \\
\hline & & & & & \\
\hline \multirow[t]{7}{*}{ Circumstance of assault } & CRQ & $53(56.4)$ & $28(22.2)$ & $81(36.8)$ & \multirow{7}{*}{$\begin{array}{l}X^{2}(5)=34.4 \\
P<0.001\end{array}$} \\
\hline & BWR & $17(18.1)$ & $53(42.1)$ & $70(31.8)$ & \\
\hline & BSE & $5(5.3)$ & $13(10.3)$ & $18(8.2)$ & \\
\hline & FDR & $12(12.8)$ & $10(7.9)$ & $22(10.0)$ & \\
\hline & LD & $1(1.1)$ & $7(5.60$ & $8(3.6)$ & \\
\hline & Others $^{\dagger}$ & $6(6.4)$ & $15(11.9)$ & $21(9.5)$ & \\
\hline & Total & $94(100.0)$ & $126(100.0)$ & $220(100.0)$ & \\
\hline \multirow[t]{5}{*}{ Categorization of violence by WHO typology } & CVA & $73(77.7)$ & $73(57.9)$ & $146(66.4)$ & \multirow[t]{5}{*}{ Fisher's exact; $P<0.001$} \\
\hline & CVS & $9(9.6)$ & $41(32.5)$ & $50(22.7)$ & \\
\hline & IPV & $4(4.3)$ & $1(0.8)$ & $5(2.3)$ & \\
\hline & FVNP & $8(8.5)$ & $11(8.7)$ & $19(8.6)$ & \\
\hline & Total & $94(100.0)$ & $126(100.0)$ & $220(100.0)$ & \\
\hline
\end{tabular}

${ }^{*} C R Q$, conflict in residential quarters; $B W R$, business and work related; $B S E$, bars and social events; $F D R$, family and dating related; $L D$, land dispute; $C V A$, community violence by acquaintance; CVS, community violence by stranger; IPV, intimate partner violence; FVNP, family violence by non-partner. ${ }^{\dagger} S c h o o l$, church, street 
Table 4 The mechanism of assault and the assailant's gender in 207 cases of non-fatal interpersonal violence

\begin{tabular}{llll}
\hline \multirow{2}{*}{$\begin{array}{l}\text { Weapon of } \\
\text { assault }\end{array}$} & \multicolumn{3}{l}{ Gender of assailant(s) } \\
\cline { 2 - 4 } & $\begin{array}{l}\text { Female(s) } \\
\text { Count (\%) }\end{array}$ & $\begin{array}{l}\text { Male(s) } \\
\text { Count (\%) }\end{array}$ & $\begin{array}{l}\text { Total } \\
\text { Count (\%) }\end{array}$ \\
\hline Sharp weapon & $4(9.1)$ & $36(22.1)$ & $40(19.3)$ \\
Blunt weapon & $15(34.1)$ & $60(36.8)$ & $75(36.2)$ \\
Body parts & $19(43.2)$ & $54(33.1)$ & $73(35.3)$ \\
Glass and bottle & $6(13.6)$ & $19(11.7)$ & $25(12.1)$ \\
Gun & $1(2.3)$ & $6(3.7)$ & $7(3.4)$ \\
Others & $1(2.3)$ & $6(3.7)$ & $7(3.4)$ \\
Total & $44(100.0)$ & $163(100.0)$ & $207(100.0)$ \\
\hline
\end{tabular}

$X^{2}(6)=5.946 ; P=0.43$

Table 5 shows the anatomic site and type of injury received by the victims. Craniofacial region followed by the upper limbs were the most frequently injured sites.

\section{Discussion}

The WHO World Report on Violence and Health 2002(Krug et al., 2002) proposed a classification of violence into three broad categories: self-directed violence, interpersonal violence and collective violence. Selfdirected violence, the type of violence that a person inflicts on him or herself, includes suicide, self-abuse and selfmutilation. Interpersonal violence, on the other hand, is inflicted by one person or a small group of persons on another. It is subdivided into family and intimate partner violence, in which the perpetrator is a family member and community violence, which is violence between individuals who are unrelated, who may be friends, acquaintances

Table 5 The site and type of injury in the studied victims of non-fatal interpersonal violence

\begin{tabular}{llll}
\hline Variable & & Frequency & Percent \\
\hline Anatomic site of injury & Cranio-facial & 155 & $54.8 \%$ \\
& Upper limb & 72 & $25.4 \%$ \\
& Trunk & 28 & $9.9 \%$ \\
& Lower limb & 28 & $9.9 \%$ \\
& Total & 283 & $100.0 \%$ \\
Type of injury & Abrasion & 36 & $14.4 \%$ \\
& Contusion & 29 & $11.6 \%$ \\
& Dental loss & 8 & $3.2 \%$ \\
& Fracture & 4 & $1.6 \%$ \\
& Human bite & 28 & $11.2 \%$ \\
& Incision & 16 & $6.4 \%$ \\
& Laceration & 80 & $32.0 \%$ \\
& Ocular trauma & 11 & $4.4 \%$ \\
& Puncture or stab & 38 & $15.2 \%$ \\
& Total & 250 & $100.0 \%$ \\
\hline
\end{tabular}

or strangers. The third of the broad category, collective violence is defined as violence inflicted by organized groups, terrorist organizations and sovereign states in pursuit of social, religious, economic and political agenda (Krug et al., 2002). War between nations is included in this category of violence.

The pattern, consequences and manifestations of violence have been found to be different among populations, gender and age groups (WHO, 2014). The current research shows that males constitute majority of victims $(53.7 \% ; 126 / 220)$ and perpetrators $(79.3 \% ; 169 / 213)$ of interpersonal violence in Enugu, most notably adult males in second, third decade of life. This is similar to findings from many previous studies (Brennan et al. 2006; Eni et al.2009; Fothergill and Hashemi, 2008; Nkombua, 2007). However, the $57.3 \%$ proportion of male victims found in the present study falls short of the high figures of between 72 and $94 \%$ reported in these previous studies, which clearly show that males bear the brunt of interpersonal violence. The work by Okulate (2005) is unique in its finding of more female victims.

Risk factors for interpersonal violence have been organized into four ecological levels: individual factors, relationship factors, community factors and societal factors (Krug et al., 2002). The consensus presently is that no single factor explains why an individual becomes a victim or a perpetrator of violence. Rather, violence manifests as a result of complex interaction among factors in the four ecological levels (Krug et al., 2002). Explanation of sex differences in behavior and aggression and enquiry into why the male gender is a foremost risk factor for interpersonal violence, has been a subject of interest to social scientists (Wood et al. 2002; Archer, 2004). Authorities in Psychology have advanced theories and elaborated research evidence that highlight Sexual behavior, reproductive competition, neuro-hormonal factors, gender constructs and cultural expectations as underlying factors of sex difference in aggression and violence (Archer, 2004). In our society as in many others, the cultural expectation of the male role borders on machismo. The male is expected to "stand up and fight."

In Enugu, interpersonal violence cases reported to the police authorities usually happened between two individuals. Sixty six percent $(145 / 220)$ of the victims in this study were found to have been assailed by one person. This agrees with a report from UK, which noted that $62 \%$ of 24,660 cases of interpersonal violence were perpetrated by a single person attacker (Brennan et al., 2006). However, as a pointer to variable manifestations of violence in different populations, Okulate(2005) reported that community violence in Port-Harcourt involved a group of young persons, often strangers and mostly operating in gangs (Okulate, 2005). 
The distribution of cases and the settings in which interpersonal violence occurred as found in this study are quite instructive. Conflict in residential quarters accounted for the highest number(36.8\%) of cases of interpersonal violence followed by disagreement during work- or business-related transactions $(31.8 \%)$.This pattern highlights a yet to be reported promoter of interpersonal violence in Nigerian cities-inadequate housing. Even though housing had been identified as a risk factor for interpersonal violence (Krug et al., 2002; Rosenberg et al. 2006), it seems the precise way in which it contributes to violence varies with respect to categories of violence and populations of people. For instance, Michael Yonas et al. (2007) identified vacant housing together with lack of employment opportunities, paucity of local businesses, inadequate trash management and poor street lighting as neighborhood level factors which promote youth violence in some areas of Baltimore city. In their study, vacant and dilapidated housing in the neighborhood was identified as clandestine rendezvous for illicit drug use and free space for stashing and selling of guns, thus fueling youth and street violence in the communities in question (Yonas et al., 2007). Street violence constituted a minor proportion of cases seen in the present study and housing as a contributing factor to violence does so in the context of inadequacy and concomitant overcrowding. Housing deficits in Nigerian cities as a result of rapid urbanization has long been documented (Abiodun, 1976). More recently, the World Bank estimates Nigeria has a housing shortfall of $17 \mathrm{mil}$ lion units (Parby et al.2015).The large mass of people who throng the urban cities in search of employment live mostly in rented apartments in which multiple households are accommodated in one dwelling or compound. In this housing arrangement, unrelated families and individuals are compelled to share housing facilities and appurtenances. Our study shows that interpersonal conflict often arose in this setting sometimes over matters as trivial as use of clothesline. It seems the prevailing tenement system in our urban city creates the milieu for a good number of reported cases of interpersonal violence and so eradication of this form of interpersonal violence would require provision of adequate housing.

One other insight from our data is the idea of interpersonal violence as a corollary to individual's socio-cultural roles, daily circumstances and life endeavors. This is seen in our finding of strong statistical association between victim's gender and circumstance or categories of violence. In our society, males and females have different roles and preoccupations. Traditionally, females are home keepers while men are expected to work and fend for their families. Thus, violence in residential quarters was mostly a female problem while business and work-related violence was found more common in males. In addition, women do not traditionally own land in our society so landrelated violence was, in our study, found to be predominantly a male issue.

The low figure (2.3\%) of intimate partner violence recorded in this study stands in sharp contrast to findings in recent community surveys, and is most likely due to underreporting of this category of violence to the police. Ezeudu et al. (2019) reported 43.7\% prevalence of intimate partner violence one year before pregnancy, in 702 women attending antenatal clinics in Enugu State. Similarly a survey of 300 women in south western Nigeria reported everexperienced spousal violence prevalence rate of $47.3 \%$ and spousal violence prevalence rate of $32 \%$ in the 12 months preceding the survey (Akinsanya and Odusina, 2012). In another study, Anolue and Uzoma ( 2017) found a prevalence of $56 \%$ among 682 women surveyed in a community setting. There are cultural and societal norms which dissuade partners in abusive relationship from reporting to police and legal authorities. For this type of violence to be curtailed, a program designed to encourage victims of domestic violence to report is needed. Such program should include divesting the framework for receiving complaints of domestic violence from the Police authorities whose operational procedure in Nigeria can be quite harrowing for both victim and assailant. In addition, introduction of a standardized protocol could streamline and improve evidence gathering as well as health management of victims of sexual violence (Zerbo 2018).

This study also shows that cranio-facial region received the most injuries in interpersonal violence. This may be due to the fact of its exposure and accessibility. We also found frequent injuries to the upper limbs. This is not surprising given that the upper limb is, by reflex, deployed in defense during assaults.

Objects deployed as weapons of assault included bottles, wood, workman tools, knife and gun. A motley of other objects such as razor blade, metal keys, hot pressing iron, elephant tusk, pestle and leather belt were also used. Body parts were readily used. The array of weapons suggest that most times, whatever object was handy in the heat of conflict became a weapon of assault. Guns were only involved in seven of the incidents and on these occasions, they were rather used as bludgeons (gun whipping) instead of firearms. This suggests some restraints and reluctance to kill in some of these incidents. Few private individuals own guns in Nigeria, as gun ownership requires strict licensing process.

Regarding the type of injury sustained, 32\% frequency of laceration seen in our study is less than $41 \%$ reported by Nkombua ( 2007) but more than 16\% frequency in the study by Brink et al. (1998) who also observed that "pattern of assault injuries may differ between countries and communities due to cultural and social factors and tradition." In addition, more than $70 \%$ of the weapon or mechanism of assault in 
our study had capacity for inflicting only blunt injuries and this may explain the level of laceration seen in our study.

All subjects in this study were referred to us by the police and this could have introduced some form of bias and limited the number and spectrum of interpersonal violence seen in this study. Many people in Nigeria are overly cautious of dealing with the police authorities because of the difficulties of making a case. This fact was very much demonstrated by Olasoji and colleagues in a study comparing the rate of reporting of assault cases to the police authorities and to the Accident and Emergency unit of a university teaching hospital in Maiduguri, Nigeria. In their study, $58 \%$ of the cases presenting at the accident and emergency reported to the police while $42 \%$ preferred not to involve the police. In addition, only $41 \%$ of cases reported to the police were captured in police records (Olasoji et al. 2005).

Violence is a legal and criminal justice issue as well as a public health concern. Confronting violence with the public health approach requires epidemiological studies to determine the major risk factors and priorities for action.

\section{Conclusion}

This study has revealed some facets of interpersonal violence peculiar to our society and which hitherto, have not been reported and which could be of use in a future preventive effort. Conflicts among tenants in residential quarters accounted for the highest number of cases of interpersonal violence followed by disagreement during work- or business-related transactions. Males in active, productive age are mostly involved both as victims and as perpetrators of interpersonal violence. Circumstances and categories of violence showed strong statistical association with gender of victim. Interpersonal violence often occurred in the context of and as a corollary to a person's life endeavors and daily activities.

\section{Abbreviations}

CDC: Center for Disease Control; SD: Standard deviation; WHO: World Health Organization

\section{Acknowledgements}

Not applicable

\section{Authors' contributions}

NTO and SRO conceived and designed the study. OSR oversaw data acquisition. NTO analyzed and interpreted the data. NTO and SRO drafted sections of the manuscript and critically revised and approved the final version for publication. Both authors read and approved the final manuscript.

\section{Funding}

The authors declare that the research was self-funded.

\section{Availability of data and materials}

The dataset generated and analyzed during the current study are available in the Mendeley repository, [https://data.mendeley.com/datasets/4vpychsvvk/ draft?a=93dbadad-a75b-499e-a397-667401d64e2a.
In addition, the dataset used and analyzed during the current study are available from the corresponding author on reasonable request.

\section{Ethics approval and consent to participate}

This study was approved by the ethics committee of Enugu State University Teaching Hospital Parklane. Informed consent was obtained from all study participants

Consent for publication

Not applicable

\section{Competing interests}

The authors declare that they have no competing interests.

Received: 15 May 2019 Accepted: 24 October 2019

Published online: 02 December 2019

\section{References}

Abiodun J (1976) Housing problems in Nigerian cities. Town Plann Rev 47:339_ 347

Akinsanya AO, Odusina EK (2012) Spousal violence in Southwest Nigeria: prevalence and correlates. J Women's Health Care 01:1-8. https://doi.org/10. 4172/2167-0420.1000110

Anolue F, Uzoma O (2017) Intimate partner violence: prevalence, contributing factors and spectrum among married couples in Southeast Nigeria. Int J Reprod Contracept Obstet Gynecol 6:3748-3753. https://doi.org/10.18203/ 2320-1770.ijrcog20174019

Archer J (2004) Sex differences in aggression in real-world settings: a metaanalytic review. Rev Gen Psychol 8:291-322

Brennan IR, Moore SC, Shepherd JP (2006) Non-firearm weapon use and injury severity: priorities for prevention. Injury Prevention 12:395-399. https://doi. org/10.1136/ip.2006.011858

Brink O, Vesterby A, Jensen J (1998) Pattern of injuries due to interpersonal violence. Injury 29:705-709

CDC (2002) Nonfatal physical assault - related injuries treated in hospital emergency departments-United States 2000. MMWR Weekly 51:460-463

CDC (2016) Deaths: final data for 2013. Natl Vital Stat Rep 64(2):1-18

Eni U, Na'aya H, Musa A, Lawan M, Chinda J (2009) An audit of non-fatal assault injuries treated in Federal Medical Center (FMC), Nguru, north east Nigeria. Nigerian J Med 18:168-171

Ezeudu CC, Onoja A, Waziri NE, Oladimeji A et al (2019) Prevalence and correlates of intimate partner violence, before and during pregnancy among attendees of maternal and child health services, Enugu, Nigeria_Mixed method approach, January 2015. Pan Afr Med J 32(Supp 1):14. https://doi.org/10. 11604/pamj.supp.2019.32.1.13287

Fothergill NJ, Hashemi K (2008) A prospective study of assault victims attending a suburban A\&E department.Emergency Medicine Journal 7: 172-177. https://doi.org/10.1136/emj.7.3.172

Krug EG, Dahlberg LL, Mercy JA, Zwi AB, Lozano R (2002) World report on violence and health. World Health Organization, Geneva. https://doi.org/10. 1136/ip.9.1.93

Nkombua $L$ (2007) Pattern of injuries suffered by patients treated for alleged assault at Witbank General Hospital, Mpumalanga. South Afr Family Pract 49: 14a-14d. https://doi.org/10.1080/20786204.2007.10873650

Okulate GT (2005) Interpersonal violence cases reported to the police: a Nigerian study. Journal of Interpersonal Violence 20:1598-1610. https://doi.org/10. $1177 / 0886260505280348$

Olasoji HO, Tahir A, Na'Aya U (2005) Assault cases in Maiduguri metropolis: a comparative study of police and accident and emergency units' records. Niger Postgrad Med J 12:286-288

Parby Jl, Lozano GN, Mason D, Lall SV et al. (2015) Stocktaking of the housing sector in Sub-Saharan Africa : challenges and opportunities (Vol. 2) : main report World bank Washington DC.

Rosenberg M, Butchart A, Mercy J et al (2006) Interpersonal violence. In: Brennan J, Jamison DT (eds) Disease control priorities in developing countries. World Bank, Washington DC

Vos T, Barber RM, Bell B, Bertozzi-Villa A et al (2015) Global, regional, and nationa incidence, prevalence, and years lived with disability for 301 acute and chronic diseases and injuries in 188 countries, 1990-2013: a systematic analysis for the Global Burden of Disease Study 2013. Lancet 386:743-800 
WHO (1996) Violence a public health priority : WHO global consultation on violence and health, Geneva, 2-3 December 1996

WHO. (2014). Global status report on violence prevention 2014

WHO. (2017). 10 facts about violence prevention. https://www.who.int/features/ factfiles/violence/en.

Wood W, Eagly AH, Diekman A, Ember C, Gangestad S, Geary D (2002) A crosscultural analysis of the behavior of women and men: implications for the origins of sex differences. Psychol Bull 128:699-727

Yonas MA, O'Campo P, Burke JG, Gielen AC (2007) Neighborhood-level factors and youth violence: giving voice to the perceptions of prominent neighborhood individuals. Health Education and Behavior 34:669-685. https://doi.org/10.1177/1090198106290395

Zerbo S, Milone L, Scalici E, Procaccianti S, Nardello R, Ventura Spagnolo E, Piscionieri D, Argo A (2018) Medico legal procedures related to sexual assault: a 10-year retrospective experience of a Daphne protocol application. Egypt J Forensic Sci 8:4. https://doi.org/10.1186/s41935-018-0039-9

\section{Publisher's Note}

Springer Nature remains neutral with regard to jurisdictional claims in published maps and institutional affiliations.

\section{Submit your manuscript to a SpringerOpen ${ }^{\circ}$ journal and benefit from:}

- Convenient online submission

- Rigorous peer review

- Open access: articles freely available online

High visibility within the field

- Retaining the copyright to your article 